\title{
Fondo documental Digital de Anuncios Gráficos Publicitarios
}

Daniel Tena Parera | daniel.tena@uab.cat

Universitat Autònoma de Barcelona

Resumen: Se presenta el fondo de recursos digitales para la docencia e investigación en los estudios de Publicidad y Relaciones Públicas. Es el resultado de un proyecto subvencionado para preparar una web de materiales (7000 anuncios gráficos). Para el diseño del fondo se han indexado los recursos según criterios académicos y profesionales: sector, categoría, producto, anunciante y marca, texto, año, formato, color, imagen, suporte, tipografía, estética, los actores, las acciones, etc. El análisis de su uso por estudiantes indica que mejora los procesos de aprendizaje basado en el trabajo autónomo de los estudiantes de grado y también para los estudiantes de máster.

Palabras clave: Publicidad, anuncios, recursos, imágenes

Abstract: We present the digital learning resources archive for teaching and research in studies of Advertising and Public Relations. It is the result of a project to develop a web with materials (7000 ads). For the design of the archive the materials are indexed according to academic and professional criteria: sector, category, product and brand advertiser, text, year, format, color, image, support, typography, aesthetics, actors, actions, etc. The analysis of its use by the students has indicated that enhances the learning process based on the autonomous work of degree and masters students.

Key words: Advertising, ads, resources, images 


\section{Introducción}

El fondo documental digital es fruto de un proyecto subvencionado (MQD 2009-00050) para preparar una plataforma web de materiales digitales publicitarios (7000 anuncios gráficos) para mejorar de la calidad de la impartición docente y facilitar la investigación. Éstos se han seleccionado e indexado según criterios académicos y profesionales: sector, categoría (infoadex), producto, anunciante y marca, texto, año, formato, color, imagen, suporte, tipografía, estética, los actores, las acciones, etc. El estudio de su uso por parte de los estudiantes e investigadores indica que con él se agiliza y mejora los procesos de aprendizaje basado en el trabajo autónomo.

La misión del docente se concentra en crear entornos de aprendizaje donde docentes, discentes y materiales interactúen (Díaz Fondón et alt., 2005). En nuestro caso, crear un fondo digital con materiales apropiados permite que se interactúe con los materiales para seleccionar, organizar y aplicar nueva información a la resolución de problemas de conocimiento.

Para esta tarea se especificaron los siguientes objetivos:

1. Objetivos relacionados con la actividad académica: mejorar los recursos docentes digitales y ofrecer a los estudiantes nuevos recursos que faciliten el cambio docente.

2. Objetivos relacionados con el material del Fondo Documental Digital: permitir su utilización; lo que debe favorecer que el estudiante se convierta en un sujeto activo de su aprendizaje.

3. Objetivos relacionados con los estudiantes: facilitar la adquisición de conocimientos, habilidades y competencias específicas, favorecer la evaluación y la autoevaluación de los contenidos.

El proceso de trabajo realizado se concreta en los siguientes pasos:

a. Establecimiento de los criterios de catalogación (etapa de fundamentación)

b. Confección del libro de estilo del Fondo Documental Digital de Publicidad

c. Construcción del espacio docente portador de los contenidos digitales

d. Uso del espacio docente

e. Evaluación del uso

La situación actual está marcada por la saturación de recursos documentales lo que añade dificultad para encontrar referencias documentales precisas, especialmente piezas publicitarias de referencia y con la calidad suficiente. Este contexto dificulta el trabajo académico y el de investigación autónomos para los estudiantes de grado y máster. 
El origen del Fondo Documental Digital se basa en la experiencia adquirida por el grupo de investigación de la Universidad Autónoma de Barcelona en Publicidad y Relaciones Públicas $(G R P)$ en la confección de la Biblioteca Virtual BREVIA (Tena et alt., 2006), que se inició en el año 2006, con la intención de cubrir la necesidad de facilitar el acceso de los estudiantes a documentos digitales de carácter teórico. La BREVIA fue un proyecto del IDES de la Universitat Autònoma de Barcelona (UAB) orientado a desarrollar un espacio digital de materiales científicos y didácticos preparados y organizados por titulaciones según criterios de relevancia. En julio de 2006, la BREVIA estaba constituida por 100 unidades digitales consultables por los estudiantes de de Publicidad y Relaciones Públicas, básicamente libros digitalizados y enlaces web. Así pues, este trabajo previo es el germen que ha dado lugar posteriormente a la creación de una herramienta documental como es el Fondo Documental Digital de Publicidad y Relaciones Públicas.

\section{Criterios de catalogación}

El proceso de trabajo se inició con la concreción de los criterios de catalogación y la posterior elaboración del libro de estilo del fondo. No se trataba únicamente de establecer unos criterios con validez profesional. Se trataba de establecer criterios que permitiesen la clasificación o catalogación pero muy especialmente, debían permitir la recuperación de los documentos (Jiménez Esteller et alt., 2006). Se inició en este sentido el trabajo de revisión y análisis de los posibles criterios. El resultado ha sido la creación de un libro de estilo de la base de datos del Fondo Documental Digital.

En una base de datos la coherencia de los datos introductorios resulta fundamental para facilitar la posterior recuperación de la información. En este sentido, en un principio trabajamos en base a un estudio (GRP) previo que ha servido para establecer los criterios profesionales del sector publicitario utilizados para el Fondo (proyecto EL CONCEPTO 1.0, 1992-2002; Ricarte, José Ma; Roca, David; y Fajula, Anna). Estos criterios fueron posteriormente ampliados, lo que ha dado lugar, finalmente, a la utilización de 22 criterios de catalogación. Estos criterios o son los que se ejemplifican a continuación.

\subsection{Variables de clasificación del Fondo de Publicidad}

Se identifican en tres ámbitos: criterios de la profesión publicitaria, criterios formales y criterios sociales.

\subsubsection{Criterios de la profesión publicitaria}

- Sector: categorizar la actividad productiva que la publicidad se destina. Serían los siguientes: 
1) ALIMENTACIÓN

2) AUDIOVISUALES

3) AUTOMOCIÓN

4) BEBIDAS

5) BELLEZA, HIGIENE Y SALUD

6) COMERCIO Y DISTRIBUCIÓN

7) ENERGÍA E INDUSTRIA

8) FINANCIERO Y SEGUROS

9) HOGAR

10) INTERNET

11) JOYERÍA, ÓPTICA Y RELOJERÍA

12) LIMPIEZA

13) OCIO Y CULTURA

14) OFICINA, INFORMÁTICA Y TELECOMUNICACIONES, TELEFONÍA

15) ONG, FUNDACIONES Y CAMPAÑAS DE MARQUETING SOCIAL

16) SERVICIOS PÚBLICOS

17) 17). TABACO;

18) VESTIMENTA

19) VIAJES, TRANSPORTES Y TURISMO

20) OTROS

- Categoría: Cada uno de los grupos básicos en los que puede incluir el producto o servicio que la publicidad es destinada.

- Ejemplo:

- Sector, Categoría

- Bebidas, Vinos

- Bebidas, Bebida alcohólica

- Producto: producto o servicio en concreto de la publicidad.

- Anunciante / marca: empresa que patrocina y firma la publicidad.

Debemos destacar tres posibles casos: 
a) Que en el anuncio aparezca como anunciante y/o marca un solo nombre.

Ejemplo:

Hoteles Sol Melià (se mantiene su idioma original)

b) Que aparezca el nombre del anunciante y el de la marca. Se escribirá de acuerdo a lo indicado en el anunciado del apartado (primero el nombre del anunciante, y después tras una barra y un espacio de separación el de la marca).

Ejemplo:

- Anunciante/ Marca

- Puleva

- Maggi

- Nestlé/ Bonka

- Kellogg's/ All-bran

- Año: período en que fue publicado. Con la imposibilidad de determinar el año exacto, se puede definir la década.

Se deberá indicar en cifras el año completo.

Ejemplo:

- Mal: 99

- Correcto: 1999

Si no se identifica el año exacta, se deberá indicar la década aproximada a la que pertenece con el año inicial de la misma. Cada década empieza en el año 0 y finaliza en el año 9. Así será 1990 la indicación a la década correspondiente a los años entre 1990 y 1999.

Ejemplo:

- $\quad$ Mal: $90 ; 91 \ldots$

- Correcto: 1990 


\subsubsection{Criterios de clasificación formales o gráficos}

Los documentos se clasifican a partir de las siguientes variables formales:

- Tipo de publicidad: en esta categoría debemos establecer si la publicidad es video, anuncio gráfico, publicidad directa, otros.

- Soporte: revista, periódico, carta, libro.

- Formato: espacio gráfico en cm que la publicidad ocupa.

- Color: La publicidad es en color o blanco y negro.

- Tipo de imagen: foto, ilustración, texto, y también la mezcla de estos tipos de imágenes.

- Texto: slogan de la publicidad. Transcribir el slogan tal como aparece en la publicidad.

- Tipografía: Se trata de identificar mínimamente la función de los textos en la pieza.

Para ello se identificará si la función de la tipografía es meramente informativa o ilustrativa y si es utilizada de manera adecuada o no. También se deberá identificar la tipología de la letra (serif...)

Opciones:

a) Estética basada en la tipografía; estética basada en la imagen; Otros.

Ejemplo:

- Tipografía/ Serif

- Tipografía/ palo seco

- Tipografía/manual

- Imagen/ Serif

- Imagen/ palo seco

- Imagen/ manual

Por ejemplo:

- Incorrecto: estética moderna.

- Correcto: tipografía; imagen, otros. 
b) Serif, sans Serif, manuales, otras.

Por ejemplo:

- Incorrecto: Arial.

- Correcto: sans serif.

- Estética: Valoración general de la pieza.

Opciones:

a) estático, dinámico, otros

b) Pesado, ligero, otros

c) Simétrico, asimétrico, otros

Por ejemplo:

- Incorrecto: Bauhaus, pop....

- Correcto: estático/ligero/asimétrico.

- Elementos formales: utilización de la figura humana, objetos formales y la mezcla de elementos.

- Elemento principal: posibilidad de determinar el elemento principal, describir.

\subsubsection{Criterios sociales de clasificación}

Consideraciones generales: Si no es procedente introducir ninguna información se deja en blanco. Se considera que los criterios pueden ir apareciendo a medida que se va ampliando el universo de anuncios. En este sentido, se deberá ir ampliando o ajustando este criterio.

- SEXO PERSONAS

- Hombres

- Mujeres

- Homo (hombres y mujeres)

- Parejas hetero

- Parejas homo 
- Familias

- Grupos

-EDAD PERSONAS

- $\quad$ Recién nacidos

- Niños

- Adolescentes

- Jóvenes

- Adultos

- $\quad$ Tercera Edad

\section{- CONDICIONES ESPECIALES PERSONAS}

Definir la condición especial que puede estar presente en los Anuncios Publicitarios con un término inequívoco y uniforme. Ejemplo: minusvalía, enfermedad...

\section{- TEMAS SOCIALES}

Definir el tema social que puede estar presente en el Anuncio Publicitario con un término inequívoco y uniforme. Ejemplo: inmigración, discriminación, esclavitud, solidaridad...

\section{- FLORA Y FAUNA}

Definir el objeto principal que aparece en el Anuncio Publicitario con un término inequívoco y uniforme. Por ejemplo: árbol, león...

\section{- OBJETOS}

Definir el objeto principal que aparece en el Anuncio Publicitario con un término inequívoco y uniforme. Por ejemplo: libro, lavadora, coche...

\section{- ENTORNO NATURAL}

Definir el objeto principal que aparece en el Anuncio Gráfico Publicitario con un término inequívoco y uniforme. Por ejemplo: paya, montaña, cocina, lavabo, tienda...; o bien: Natural; Urbano; Doméstico; Lugar de compra/venta... 


\section{- ENTORNO URBANO}

Definir donde se desarrolla la acción principal que aparece en el Anuncio Gráfico Publicitario con un término inequívoco i uniforme. Por ejemplo: plaza, calle...

\section{- ENTORNO INTERIORES}

Definir donde se desarrolla la acción principal que aparece en el Anuncio Gráfico Publicitario con un término inequívoco i uniforme. Ejemplo: cocina, lavabo, tienda, mercado, supermercado, gran superficie,,..

\section{- ACCIONES}

Definir la acción que se realiza principalmente con un verbo en su forma infinitiva. Por ejemplo: saltar, llegar, mirar...

\section{Diseño del Fondo Digital}

En cuanto al objetivo de que los materiales estuvieran adecuadamente adaptados al entorno digital, los criterios de construcción formal de los materiales virtuales seguidos para su construcción se han orientado en los indicadores marcados por Manuel Cebrián (2003). En este sentido, el estudio previo destacó los aspectos a considerar para garantizar la navegabilidad del usuario en el sistema y con los materiales. Éstos son los que se detallan a continuación:

- Learnability: tiempo que un lector utiliza en aprender las funciones y como retener este conocimiento a través de las secuencias interactivas.

- Usability: aspecto que hace referencia a si el usuario entiende las herramientas de navegación, si comprende su funcionamiento, si lo utiliza satisfactoriamente, etc.

- Consistency: hace referencia a aquello que es necesario, de manera intuitiva, para aprender las herramientas de navegación.

- Flexibility: flexibilidad para adaptarse a la variedad de usos disponibles, estilos de aprendizaje y funciones.

En la búsqueda de los antecedentes formales para el fondo, Internet resultó ser una gran fuente de información, de recursos y de referencias interesantes. En este sentido, la búsqueda de sitios fiables y realmente útiles en el ámbito de internet-buscadores ha sido una tarea un tanto complicada, especialmente atendiendo al objetivo de seleccionar un modelo adecuado a nuestras necesidades (Redondo S., 2005). Dos eran las posibilidades de funcionamiento de nuestra base de datos de suministradores de imágenes: como base de 
datos de productos gratuitos o de pago. El "Google images" es un buen ejemplo para el primer caso y gettyimages para el segundo (Figura 1 ).
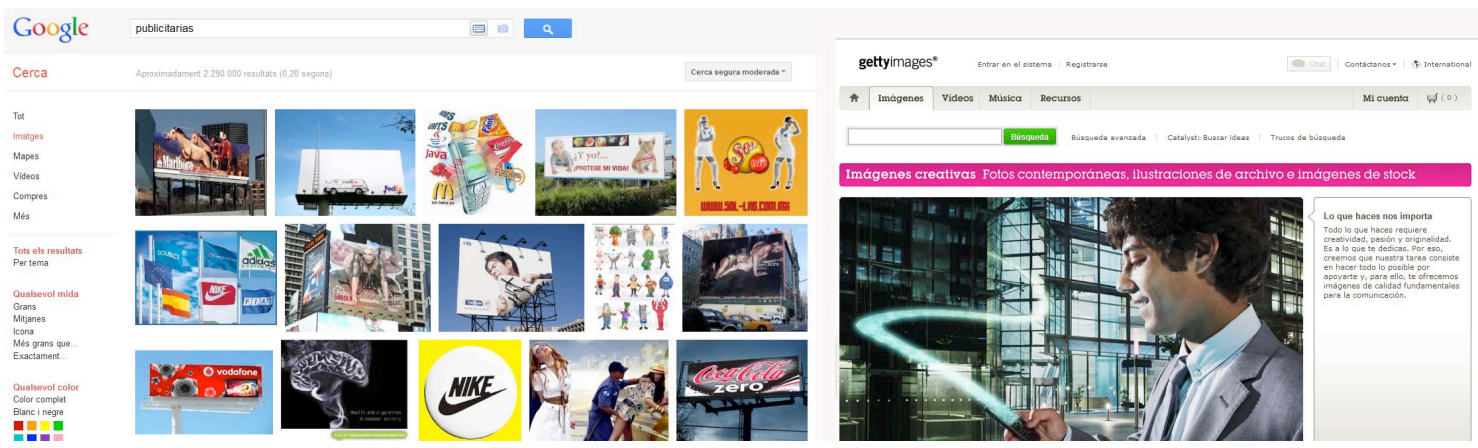

Pero lo que nos hacía falta era gestionar nuestras piezas publicitarias, lo que nos orientaba hacia un modelo más cerrado como puede ser "Gettyimages". En este caso se trata de un portal especializado en imágenes creativas. No obstante, este modelo tampoco se adapta a nuestras necesidades. Otras opciones que se tenían eran: ADFORUM, AD ACCES, AD OF THE WORLD, COLORIBUS Y CORBIS (Figura 2). En todos los casos, se aproximan a lo que se pretende pero no acaban de ofrecer la libertad de gestión requerida. 
Figura 2. ADFORUM, AD ACCES, AD OF THE WORLD, COLORIBUS Y CORBIS.

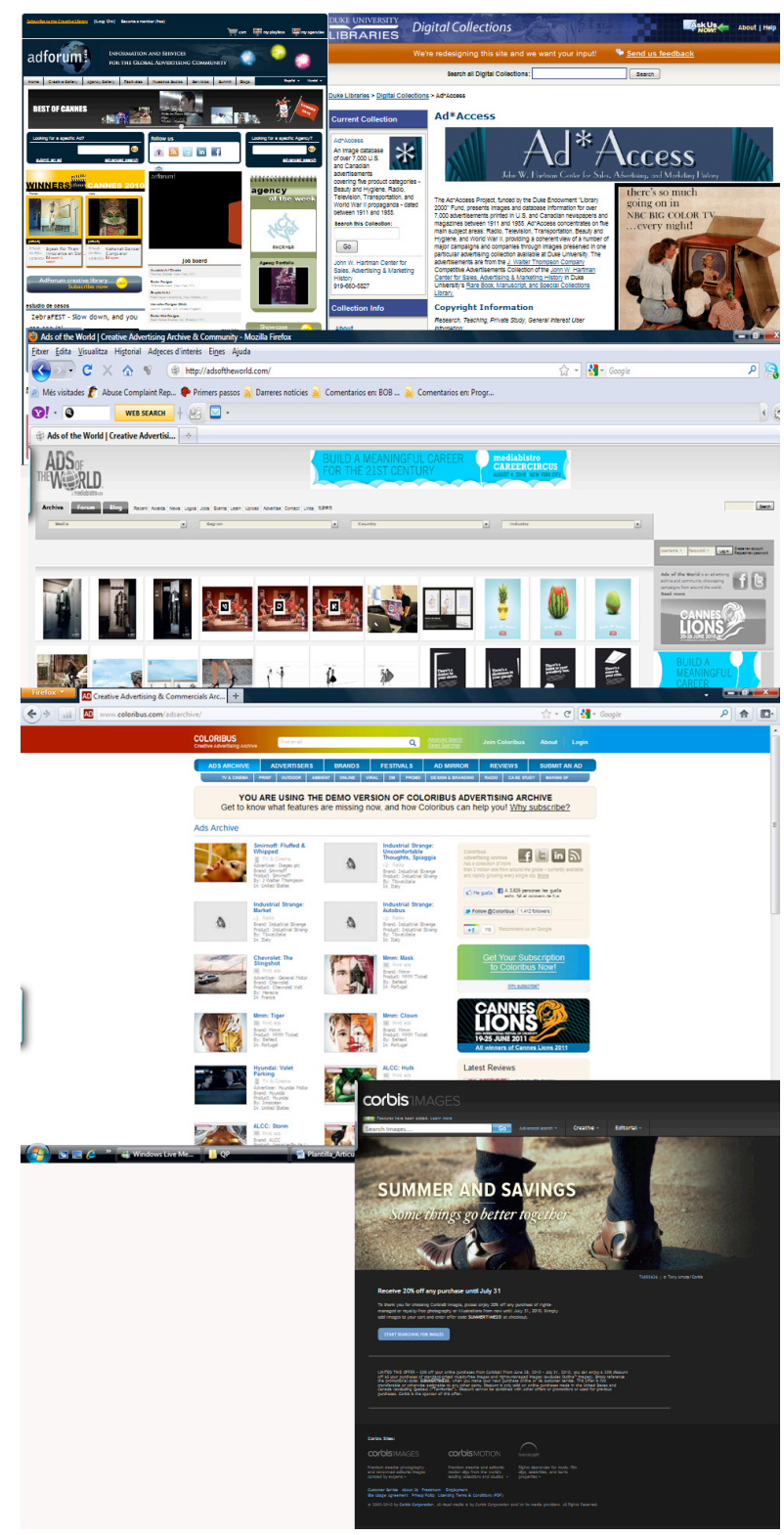

Es en este momento cuando nuestro trabajo nos encaminó a la necesidad de construir una web específica que permitiese la gestión y, especialmente, poder gestionar el acceso de los usuarios, la incorporación de nuevos recursos y también poderlo hacer de manera autónoma y remota. Por tanto, se opta por construir una web: El fondo documental digital de publicidad y relaciones públicas. Todos los suministradores de imágenes estudiados son tomados como referencia para esa tarea.

Por otra parte, era necesario experimentar con la catalogación de los materiales. En este sentido, con un extenso material en formato papel (depositado en el grupo de investigación GRP) y con nuevas adquisiciones, se inició la indexación de los materiales según el libro de estilo confeccionado y presentado anteriormente. De esta manera se ha podido formalizar la 
primera oleada de materiales (2010) lo que ha permitido llegar a indizar más de 7100 Anuncios Gráficos Publicitarios como los que se muestran a continuación (Figura 3).

Figura 3. Ejemplos de piezas del Fondo Documental Digital de Publicidad.

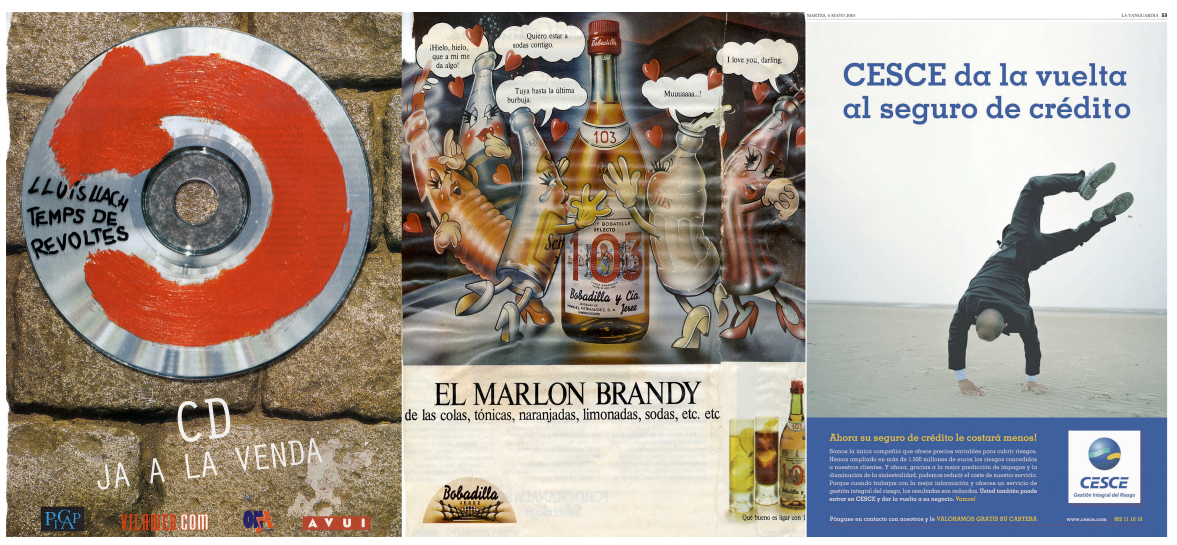

Todos los materiales han sido analizados y clasificados siguiendo una metodología de trabajo basada en la codificación por parejas. De esta manera la clasificación era más rápida y, especialmente, mucho más rigurosa. En el caso de que los codificadores tuvieran dudas, consultaban al investigador de referencia. Visionados los documentos y analizados, se introduce la codificación en el documento Excel para facilitar su catalogación. Posteriormente, los documentos, en caso de ser analógicos han sido digitalizados para permitir introducir la información tratada a la página web del fondo. La visión general del archivo en Excel nos permite ver la gran cantidad de información de cada una de las piezas que ha sido necesario introducir en la base de datos.

En total han sido 28 criterios diferentes los que se pueden utilizar en la base de datos. Se puede localizar piezas a través de los siguientes criterios de indexación: formato, color, imagen, soporte, carácter de la tipografía, tipo de letra, estático o dinámico, pesado o ligero, simétrico o asimétrico. Igualmente, se pueden realizar búsquedas a partir de los criterios: sexo personas, edad personas, condiciones especiales personas, temas sociales, flora y fauna, objetos espacios, acciones descripción general. Finalmente, la última opción, da acceso al documento digital a través del localizador del documento digital.

Es a partir de este momento cuando podemos confeccionar ya definitivamente la página web con los materiales digitalizados y cuando se pueden realizar búsquedas selectivas de los anuncios publicitarios mediante la preselección de algunas etiquetas.

En la dirección del grupo de publicidad y relaciones públicas, creada para este menester (http://www.grupopublicidadyrelacionespublicas.com/fons/) se accede a la primera pantalla del fondo documental digital de publicidad. En la pantalla principal se pueden ver ya los criterios utilizados para la indexación de documentos; sector, categoría, producto, marca, slogan, título, cuerpo de texto, año. 
El Fondo Documental Digital de Imágenes publicitarias permite localizar los anuncios indizados a partir de diferentes criterios (14) utilizados en la base de datos (Figura 4).

Figura 4. Pantalla principal de búsqueda del Fondo y aspecto de los resultados obtenidos de una búsqueda.

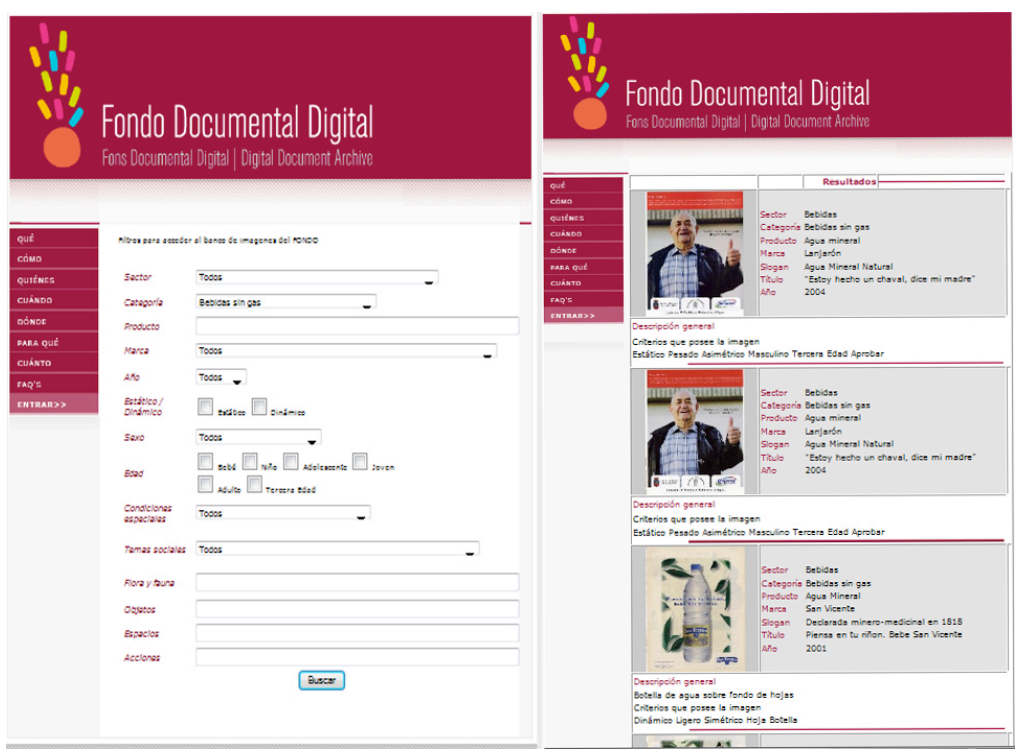

\section{Resultados y Conclusión}

El trabajo realizado se concreta en:

a. Elaboración del Libro de estilo del Fondo Documental Digital.

b. Catalogación e indexación de piezas: más de 7100 Anuncios Gráficos publicitarios.

c. Construcción de una web site.

e. Implementación masiva del uso del fondo por parte de los estudiantes.

El proceso seguido hasta aquí nos ha permitido la evaluación de la percepción de los estudiantes cuando han usado el fondo (estudiantes de cuarto curso de la licenciatura de Publicidad y Relaciones Públicas, curso 2009-2010). Esta evaluación nos indica los siguientes datos generales:

1) Aumento del aprendizaje autónomo.

2) Mayor sensación de adquirir conocimientos al visualizar mejor la actividad práctica.

3) Mejora de la vinculación entre las actividades de aprendizaje y los contenidos teóricos. 
4) Mayor aprovechamiento del tiempo de aprendizaje.

Además, en base a las informaciones obtenidas en una entrevista en profundidad a dos estudiantes que tuvieron la oportunidad de trabajar más profundamente en el fondo para la realización de un trabajo de curso y de la posterior revisión de los estudiantes y profesores de la evaluación de la asignatura, se pueden extraer las siguientes conclusiones:

1) El acceso al Fondo Documental Digital aporta muchos aspectos positivos a los estudiantes para afrontar las actividades de las asignaturas de la licenciatura de Publicidad y Relaciones Públicas. Principalmente, respecto de las asignaturas de marketing, comunicación comercial, estrategia creativa, diseño y dirección de arte.

2) La posibilidad de poder acceder a una amplia gama de anuncios en versión digital o posteriormente su versión en papel ahorra mucho tiempo al estudiante, a la vez que le aporta una mayor amplitud de posibilidades. Esto le permite inspirarse o encontrar antes aquello que busca de manera inmediata.

3) El fondo permite seleccionar toda clase de anuncios según su categoría, producto y formatos, entre otros criterios. Los recursos que se encuentran en Internet son de menor cualidad respecto de los que ofrece el fondo.

4) Son muchas las actividades a lo largo de la licenciatura que se pide a los estudiantes la recopilación de anuncios para realizar análisis diversos. Análisis tanto visuales como para investigar la intención del mensaje o el objetivo publicitario de la marca. En este aspecto el fondo aporta inmediatez, comodidad y fácil acceso.

La conclusión final del diseño, creación y uso del fondo documental digital de imágenes publicitarias no puede ser más satisfactoria. En la actualidad, el Fondo se ha utilizado de nuevo en el curso 200-2011 con los estudiantes de la licenciatura y, además, se está utilizando para la selección de muestras de piezas publicitarias en el estudio de trabajos de investigación conducentes al doctorado. 


\section{REFERENCIAS BIBLIOGRÁFICAS}

Ayala, Francisco (1972): "Propaganda y democracia", en Hoy ya es ayer. Madrid, Moneda y Crédito, pp. 193-200.

Chapman Brown, Harold (1929): "Advertising and Propaganda: A Study in the Ethics of Social Control", en International Journal of Ethics, vol. 40, n 1, pp. 3955.

Cogswelt, David (1997): "History is Not Over. Mechanisms Exist to Change the System. A Conversation with Noam Chomsky", no 18, en http://www.halpc.org/ clyndes/Chomsky.html (consultado: 12/06/2007).

GARCÍA UCEDA, Mariola (1997): Las claves de la publicidad. Madrid, ESIC.

CEBRIÁN, Mariano (2003): Enseñanza virtual para la innovación universitaria. Madrid, Narcea.

DíAz Fondón, Ma Ángeles, Riesco Albizu, Miguel y Martínez Prieto, Ana Belén (2005): "Hacia el aprendizaje activo: un caso práctico en la docencia de Sistemas operativos" en Novática. Revista de la Asociación de Técnicos en Informática, no 174, pp. 54-58.

JimÉnez EstelleR, Laureano, Estupinyà Giné, Pere y Mans Alsina, Claudi (2006): Potencial d'un entorn virtual d'aprenentatge en assignatures ECTS semipresencials. La perspectiva del professorat. Madrid, CES Cardenal Spínola CEU.

REDONDO, Sara (2005). Estudio comparativo internacional sobre modelos estandarizados de evaluación y marcas de calidad de materiales educativos digitales. Madrid, Centro de Investigación y Documentación Educativa (CIDE).

TenA, Daniel, Fernández CuestA, Jordi y TÉBAR, Nuria (2006). Biblioteca virtual para el trabajo en ECTS. En Congreso EDUTEC 2006, La educación en entornos virtuales. Tarragona.

Referencias de webs

Adforum: http://www.adforum.com/adfolio/index.asp

Ad Acces: http://library.duke.edu/digitalcollections/adaccess/

Ads of. The World: http://adsoftheworld.com/

Coloribus: http://www.coloribus.com/adsarchive/

Corbis: http://www.corbisimages.com/

Gettyimages: www.gettyimages.com

Fotolia: http://es.fotolia.com/ 
Fons Documental Digital de Publicidad:

http://www.grupopublicidadyrelacionespublicas.com/fons/

[Recibido: 14 de diciembre de 2012. Aceptado: 30 de septiembre de 2013]. 